\title{
O Vídeo como potencializador da arte educação digital crítica
}

Vídeo as empowerment for a critical digital art education

Paulino Antonio Da Silva Moreira

Universidade Europeia do Atlântico

\section{Resumo}

O presente artigo discute a utilização do vídeo como potencializador da earte/educação, essa pesquisa nasceu como conclusão do curso de Especialização em Arte/Educação Intermidiática Digital, intitulado "O vídeo como potencializador da arte/educação digital crítica". A pesquisa aqui apresentada discute a necessidade de desenvolver a consciência crítica dos estudantes por meio do vídeo, abordando uma temática de violência, problematiza-se os atos corriqueiros e que devido a tanta incidência dos mesmos, tornam-se comuns, e é isso que a ação pedagógica procura mudar, ela pega um ato do dia-a-dia não pensado e faz pensar. Utilizar-se-á pesquisas bibliográficas e leituras diversas para potencializar a arte/educação, com o objetivo da ação pedagógica para promover a leitura crítica de um mundo descortinado e o desenvolvimento da consciência plena e crítica do mundo, em que a ação pedagógica crítica e criativa visualiza as diversas possibilidades viáveis para atingir os objetivos educacionais desejados na educação, definindo as ações pedagógicas.

Palavras-chave: arte/educação; Consciência crítica; ação pedagógica.

\begin{abstract}
This article discusses the use of video as enabler of e-art/education, this research was born as completion of the course of specialization in Art / Education Digital Intermidiática entitled "Video as a potentiator of art/criticism digital education." The research presented here discusses the need to develop a critical awareness of students through the video, addressing a theme of violence, everyday acts to problematize and that due to such incidence thereof, become common, and that is what pedagogical action seeks to change, it takes an act of the day-to-day not thinking and makes you think. Using literature searches, and reading to enhance the art/education, with the goal of pedagogical action to promote critical reading of a world opens up and development of mindfulness and critical of the world in which critical pedagogical action and creative view the various viable possibilities to achieve the desired educational goals in education,
\end{abstract}

Revista Digital do LAV - Santa Maria - vol. 9, n. 1, p. 145 - 161. - jan./abr. 2016 ISSN 1983 - 7348 http://dx.doi.org/10.5902/1983734822001 
defining the pedagogical actions.

Keywords: Art/Education; critical awareness; pedagogical action.

1 Orientando de pós-graduação lato sensu do curso de Especialização em Arte/Educação Intermidiática Digital, da Universidade Federal de Goiás. Possui graduação de Tecnologia em Design de Moda pela Universidade Estadual de Goiás (UEG). Especialista em Inovação em Mídias Interativas pela Universidade Federal de Goiás (InMídias/UFG). Mestrando em Educação pela Universidade Europeia do Atlântico (UNEATLANTICO).

2 Orientadora possui graduação em Educação Artística - Licenciatura Plena pela Fundação Armando Álvares Penteado (1997), mestrado em Artes pela Universidade de São Paulo (2004), doutorado em Artes pela Universidade de São Paulo (2008). Atualmente é professora adjunta da Escola de Música e Artes Cênicas da Universidade Federal de Goiás (EMAC/UFG), vice-coordenadora do programa de pós-graduação Stricto Sensu (mestrado e doutorado) Interdisciplinar em Performances Culturais (EMAC/UFG). É coordenadora do curso de especialização em Arte/Educação Intermidiática Digital (EMAC/UFG) e tem experiência na área de Artes, atuando principalmente nos seguintes temas: Intermídia, Cultura digital, e-Arte/educação. "Texto revisado pelo orientador".

\section{Introdução}

Esta pesquisa nasceu da curiosidade em aprender mais sobre a earte/educação digital crítica e como trabalho de conclusão do curso Especialização em Arte/Educação Intermidiática Digital, ofertado pela Escola de Música e Artes Cênicas da Universidade Federal de Goiás (EMAC/UFG).

Por meio da autonomia, aliada a e-arte/educação digital crítica no processo de ensino/aprendizagem, o pensamento autônomo potencializa os saberes intrínsecos na mídia digital e retira o sujeito do pensamento acrítico, livre de informação, e o torna crítico com conhecimento e aprendizado.

Deste modo segundo Barbosa (2008, apud CUNHA, 2012, p.161) a earte/educação converge para a formação perceptiva, em que "perceber é conhecer". Ela traz a possibilidade de o sujeito tornar-se autônomo deixando a passividade.

Buscamos uma prática de ensino/aprendizagem earte/educativa que possibilitasse aos alunos experimentar ações significativas para a construção de pensamentos crítico/autônomos, oriundos da criticidade acerca de uma situação problemática contida na realidade tangível em que vivem. (CUNHA, 2012, p. 23).

Levando em consideração esta teoria de Cunha, dividiu-se esta pesquisa em duas partes. A primeira discute a arte/educação digital crítica, que envolve a autonomia/auto-governança e apresenta que o ensino de arte possibilita questionamentos e desenvolvimento da capacidade crítica, elementos essenciais 
para formação dos estudantes.

A segunda parte apresenta algumas formas de analisar e usar o vídeo "Pai me ajude, nasci menina", numa possível ação pedagógica com alunos do 90 ano do ensino fundamental de uma escola pública no estado de Goiás. A temática problematiza uma situação de assédio sofrida por uma garota em espaço escolar e extraescolar, situação ignorada por professores e família e que se agrava a ponto de ocorrer um estupro. Ao trazer o vídeo a discussão, problematiza-se os atos corriqueiros e que devido a tanto incidência dos mesmos, tornam-se comuns. Traz-se ainda a possibilidade de o educador trabalhar a autonomia crítica dos estudantes.

A falta dessa autonomia crítica restringe a auto-governança e torna o sujeito que aprende vulnerável a ditadura cultural da elite dominante, justificando a necessidade de a escola e o educador trabalhar o desenvolvimento da consciência crítica do aluno. Por outro lado, tem-se o objetivo de utilizar o vídeo "Pai me ajude, nasci menina" como potencializador da ação pedagógica.

\section{Resultados e Discussão}

Embora o ensino da Arte ocorra pela mediação de educadores que trabalham com educação há décadas, na contemporaneidade esse ensino exige procedimentos didáticos novos e diferenciados, um convívio maior com a earte/educação e suas linguagens e processos comunicacionais que viabilizem, de acordo com Fernanda Cunha (2012), a educação intermidiática crítica por meio da e-arte/educação e da educação libertária, as quais promovem a leitura crítica de um mundo descortinado e o desenvolvimento da consciência plena e crítica do mundo, trazendo ao sujeito a possibilidade de fazer escolha autônoma em suas reavaliações, reinterpretações, ressignificações de seus valores.

Assim a e-arte/educação promove uma interconexão com o mundo onde o sujeito desenvolve a consciência crítica e manifesta o seu posicionamento reflexivo no mundo e sobre o mundo.

Concebemos a e-arte/educação como construção de conhecimento, em que cognição está inserida no "processo pelo qual o organismo torna-se consciente de seu meio ambiente", cria o que Barbosa (2008, apud CUNHA, 2012, p. 161) por meio de experiências significativas ao longo de um processo, pois "refinar os sentidos e alargar a imaginação é o trabalho que a arte faz para potencializar a cognição".

Revista Digital do LAV - Santa Maria - vol. 9, n. 1, p. 145 - 161. - jan./abr. $2016 \quad$ ISSN 1983-7348 http://dx.doi.org/10.5902/1983734822001 
A e-arte/educação digital crítica é muito mais do que recurso de ensino, ela é o fator relevante que abre espaço para discussões a respeito do pensamento humano não autônomo em nossa sociedade, ou seja, do modo como sentimos, entendemos, agimos e comunicamos, ampliando os horizontes da discussão sobre a formação de ações educacionais no processo de ensino/aprendizagem em que se pode desenvolver a consciência crítica descrita por Cunha (2012).

Essa autora defende que questionemos mais criticamente como as tecnologias digitais, seus inputs e outputs, têm sido inseridas no processo de ensino/aprendizagem, descreve a possibilidade de uma teoria libertadora baseada no diálogo, no desenvolvimento do pensamento autônomo e da consciência crítica, onde o sujeito é capaz de interpretar o mundo, que a pessoa seja capaz de entender o que lê.

As tecnologias digitais no ensino de artes podem colaborar para 0 desenvolvimento do pensamento autônomo do aluno, a professora Ana Mae Barbosa, nos provoca uma reflexão que para o desenvolvimento da identidade cultural e da cognição/percepção, devemos manter um diálogo investigativo para o fortalecimento do ensino das artes, e quando inseridos nas escolas potencializam os tipos de saberes, ou de conhecimentos intrínsecos às mídias digitais, colaborando para a formação humana.

Diante das novas dinâmicas culturais, inauguradas pelas tecnologias comunicacionais, Ana Mae Barbosa, aponta que os educadores reconsiderem seu papel diante das aprendizagens proporcionadas pelos diversos modos de informação e do conhecimento da consciência do entendimento analítico/crítico. Nesse sentido, "A prática sozinha tem se mostrado impotente para formar o apreciador e fruidor de arte." (BARBOSA, 1991, p. 41).

É seguindo esse pensamento sobre o entendimento analítico/crítico e reconsiderando o papel do educador no cotidiano do aluno que foi escolhido $o$ vídeo como potencializador do desenvolvimento da consciência/crítica, como é visualizada na escola e no cotidiano do sujeito, como é aplicada na sociedade é esse comprometimento que podemos ver de Cunha e Barbosa.

O vídeo condiciona o aluno para que não desenvolva seu pensamento crítico. A sociedade não ressignifica valores e facilita que o pensamento massivo acrítico se perpetue. Por sua vez, quando o educador promove o uso do vídeo como intermediador de sua ação pedagógica, possibilita o surgimento de uma cultura educacional concreta, com pensamento crítico e autônomo, assegurando um processo educativo relevante para o educando. 
Assim, "Essa autonomia específica do ser humano, [...] lança o homem a um domínio que lhe é exclusivo - o de fazedor da história e da cultura." (CUNHA, 2012, p.160).

Paulo Freire (2011) defende que só o educador é capaz de levar alguém a esse processo. Se o educador não for crítico, não desenvolver sua criticidade, isso não acontece. Quanto mais ele está comprometido com a educação, mais se preocupará em estudar para melhorar o outro, por isso precisa refinar sua criticidade para ter a capacidade de ver o que o outro precisa, mesmo que esse outro não saiba disso. Isso é um privilégio que nos leva a coadunar com a fala da professora Fernanda Cunha, ditas em encontros presenciais da especialização, quando declara que fica "em êxtase quando consegue melhorar a outra pessoa" por meio do que ensina. Para ela, quase sempre o estudante nem sabe o que não possui, mas observando todo o processo educativo, é possível ao professor identificar deficiências de aprendizagem e levar o educando a ter o que antes não tinha.

Diante dos diálogos possíveis com a e-arte/educação digital crítica e as mídias, educadores necessitam atualizar suas práticas pedagógicas em face das mudanças nos modos de produzir e socializar o conhecimento, apresentando um constante esforço para a formação dos educandos para compreender as linguagens e os processos de comunicação. Nesse sentido, Fernanda Cunha (2012) chama a atenção para as possibilidades do diálogo da arte/educação e a internet que podem cumprir dois objetivos: um vinculado de modo significativo, onde usuários sejam produtores fundamentais da própria tecnologia. E o outro onde a internet é o melhor exemplo de uma tecnologia inventada para servir a um propósito determinado, a saber, a comunicação, que nem sequer foi sonhado por seus idealizadores. Este novo sistema "é caracterizado pela integração de diferentes veículos de comunicação e seu potencial interativo." (CASTELLS, 1999, p. 387).

A tecnologia e seu potencial interativo, para os discursos das comunicações; outro, de inserção crítica da voz da diferença representada pela imposição sistematizadora e de produção dos saberes que devem motivar e estimular o mundo da escola. Nessa perspectiva, cresce a importância do desenvolvimento de ações pedagógicas que não oponham saberes adquiridos no convívio com mídias e ações pedagógicas que se pretende atingir. Intentando fugir de dois perigos que comumente circundam tal tipo de análise. De um lado, a adesão acrítica a autoadmiração tecnológica que tanto seduz como reduz e, de

Revista Digital do LAV - Santa Maria - vol. 9, n. 1, p. 145 - 161. - jan./abr. $2016 \quad$ ISSN 1983-7348 http://dx.doi.org/10.5902/1983734822001 
outro, o repúdio assustador, que responsabiliza os meios de massa pela alienação que abastarda o saber e desfigura os valores humanos.

Faz se necessário eliminar às diferenças educacionais sectárias, de forma a disponibilizar uma educação digital que promova pessoas capazes de gerar, de criar, de elaborar digitalmente, [...] para enaltecer o que há de mais humano no ser humano, além de possibilitar uma educação libertariamente crítica e autônoma. (CUNHA, 2012, p. 25).

Consoante a essas proposições, vale ressaltar que é necessário fazer a relação de uma alfabetização significativa, libertária, não opor as mídias e a earte/educação digital crítica, como meio de provocar atitudes que criam a oportunidade de construir reflexões sobre os sentidos em circulação, da ressignificação de práticas culturais, da vivência de espaços criativos. A adesão acrítica, o risco da ação pedagógica abandonar-se ao sabor das novidades, como se outros agentes fossem responsáveis pela formação de nossas crianças, ou ainda, como se artefatos tecnológicos, por si só, resolvessem todas as questões relativas à educação.

Assim, a multimídia (múltiplas mídias) ou intermídia (interconexão entre mídias), pela natureza do ambiente simbólico em que se insere na vida humana, "estende o âmbito da comunicação eletrônica para todo o domínio da vida: de casa a trabalho, de escola a hospitais, de entretenimento a viagens" (CASTELLS, 1999, p. 392).

A e-arte/educação digital crítica fala sobre a autonomia. E segundo Cunha (2012) essa autonomia acontece com as mudanças sociais e valores culturais, onde a interconexão com os meios de comunicação digitais propõe um novo paradigma cultural. Onde o ambiente digital constitui o suporte e o meio desta interação, em que o virtual e o real se entrelaçam.

Vivemos tempos de mudanças constantes, mas, principalmente, tempos de iniciativa, de cooperação, e de autonomia. A educação para este tempo precisa pautar-se em uma comunicação sem fontes e receptores definidos, mas híbridos, cambiáveis e cooperantes.

Assim "Faz-se necessário eliminar as diferenças educacionais sectárias, de forma a disponibilizar uma educação digital que promova pessoas capazes de gerar, criar, de elaborar digitalmente, [...] sem distinção." (CUNHA, 2012, p.144).

Revista Digital do LAV - Santa Maria - vol. 9, n. 1, p. 145 - 161. - jan./abr. 2016 ISSN 1983 - 7348 http://dx.doi.org/10.5902/1983734822001 
Uma ação pedagógica crítica e criativa visualiza as diversas possibilidades viáveis para atingir os objetivos educacionais desejados, definindo as ações pedagógicas. Isso quer dizer que educadores devem perceber a relação entre a arte-educação digital crítica e o conteúdo, tanto no sentido da aquisição e construção do conhecimento quanto do desenvolvimento de valores e atitudes que possibilitem um olhar crítico para as produções das mídias e, ao mesmo tempo, desenvolva a expressão individual e coletiva.

Afinal, são por meio das linguagens, visuais, auditivas, audiovisuais e hipertextuais que as mídias viabilizam a expressão criativa, a inserção nos processos de produção e circulação de bens culturais e é por meio delas que também, educa. Conforme Castells (1999) o que caracteriza a atual revolução tecnológica não é a centralidade de conhecimento e informação, mas a aplicação desses conhecimentos e dessa informação para a geração de conhecimentos e de dispositivos de processamento e de comunicação da informação, em um ciclo de realimentação cumulativo entre inovação e seu uso.

A compreensão da e-arte/educação digital crítica e suas possibilidades culturais que participam da aprendizagem, ainda que o educando não tenham acesso a equipamentos tecnológicos sofisticados, alimenta processos coletivos que surgem de uma ação pedagógica alicerçada em planejamento consistente e, principalmente, na criatividade e colaboração em que a autonomia retira o sujeito da passividade, levando a questionamentos sobre a cultura e valores

[...] coíbe a possibilidade de livre expressão, de tomar decisões livremente, restringindo a capacidade de escolha e discernimento, tornando a pessoa mais vulnerável à introjeção de valores alheios e restringindo sua autogovernança, a ponto de poder ser tornar objeto de domínio. [...] os meios de comunicação interligados possuem expoente potencial de domínio, dada a vulnerabilidade de questionamento e discernimento da pessoa, imperando a ditadura da cultura da elite dominante. (CUNHA, 2012, p. 29).

Propor uma ação pedagógica pertinente aos nossos tempos - que leve em consideração a cultura dos educandos e como as mídias estão inseridas nesta cultura, implica resgatar a importância do diálogo e potencializar o papel mediador cultural que elas desempenham. Paulo Freire (1999, p. 52) define esse diálogo como a "problematização do próprio conhecimento e sua indiscutível relação com a realidade concreta, na qual se gera e sobre a qual incide, para 
melhor compreendê-la, explicá-la, transformá-la".

O papel mediador que a e-arte/educação digital critica desempenha em nossa sociedade é complexo por envolver tecnologias com graus maiores ou menores de sofisticação, grupos de pessoas com seus desejos e interesses, lógicas e procedimentos comunicacionais. A relação entre a e-arte/educação digital crítica é, antes de tudo, uma relação entre as pessoas, com ou sem instrumentos tecnológicos, sofisticados ou não.

A e-arte/educação digital crítica constrói o sujeito, como viabilizador de processos de criação e construtor do seu pensamento crítico. Uma ação pedagógica que tenha o diálogo como orientador vê a relação entre as mídias e a escola como fenômeno complexo sobre o qual refletir, agir e questionar, mas também com o qual reconhecer-se e compreender-se o torna autônomo e questionador.

O ensino de arte possibilita questionamento, busca descoberta e desenvolvimento da capacidade crítica, os quais são elementos essenciais e pulsantes que aguçam a percepção e ampliam a imaginação e, assim, dinamizam a cognição, como adverte Eisner: "refinar os sentidos e alargar a imaginação é o trabalho que a arte faz para potencializar a cognição" (BARBOSA, 2008, p. 12).

A partir dessa base, vale lembrar que ao descobrir a capacidade do vídeo para desenvolver o potencial crítico, o diálogo, é instaurada uma metodologia que possibilitará o desenvolvimento da capacidade de aprender nas devidas proporções que dinamizam a cognição, o refletir, o agir e o questionar, tornando concreto algo que antes era comum e, norteado pela e-arte/educação gerará questionamentos e decodificará a ação proposta no processo.

\section{O vídeo e suas possibilidades educacionais}

O mais importante é a criatividade para o desenvolvimento de uma ação pedagógica que dialoga com o mundo contemporâneo, com crianças conectadas e que interagem com tecnologias e com pessoas em situações que não existiam há pouco mais de uma década apenas. A única certeza de que temos, neste momento, é que vale a pena aceitar o desafio e deixar-se banhar pela possibilidade que temos de desenvolver uma ação interessante, instigante, produtiva e cativante para ser trabalhada em sala de aula.

O uso de vídeo é um processo natural para os alunos nativos digitais

Revista Digital do LAV - Santa Maria - vol. 9, n. 1, p. 145 - 161. - jan./abr. $2016 \quad$ ISSN 1983 - 7348 http://dx.doi.org/10.5902/1983734822001 
(FRANZONI; RUBIO, 2013), e um instrumento poderoso na diminuição do analfabetismo digital (CAETANO; FALKEMBACH, 2007). Exemplo disso é o You Tube, um site que permite carregar e compartilhar vídeos em formato digital, que quando usado como ferramenta complementar nas aulas traz potencial para melhorar a qualidade da reflexão em sala de aula (JORDAN, 2012; BELL, 2013), aumentar o entusiasmo e motivação dos alunos (HEITINK; FISSER; MCKENNEY, 2012) e promover compreensão mais eficaz sobre o que o se trabalha (KHALID; MUHAMMAD, 2012).

O vídeo pode desempenhar um papel educacional relevante na medida em que possibilita a apresentação contínua de informação, a visualização de modelos de aprendizagem e a sua interpretação em determinado contexto (ADAMS et al., 2013). Ele possibilita ao docente diversificar práticas de ensino, criar estratégias de exploração para conteúdos e tornar a aprendizagem dos alunos mais significativa (BOTTENTUIT JUNIOR; LISBÔA; COUTINHO, 2013). Ao permitir que o aluno tenha um papel criativo, participativo, ativo, o vídeo permite alavancar uma aprendizagem mais cativante, envolvente e facilitadora da aquisição de conhecimento (FERREIRA; OLIVEIRA, 2011).

O trabalho com o vídeo na escola tem muitas vantagens, dentre as quais, a facilidade de acesso dos alunos por celulares e pelo aplicativo do You Tube, os alunos gostam de aulas com imagens, com uso de mídias digitais.

Apesar de todo esse processo educativo e do interesse que o uso do vídeo promove entre crianças e adolescentes na escola, a visão e a capacidade desses sujeitos de interpretar alguns aspectos das imagens e seus significados ainda não estão suficientemente educadas, eles precisam ser guiados pelo educador a fim de que a atenção seja despertada e essa habilidade desenvolvida.

O educador tem papel fundamental no alcance dos objetivos na aplicação do vídeo. Sua ação pedagógica deve trazer esclarecimento do objetivo na seleção do vídeo e informar às crianças o que se espera ao final da discussão, deixando espaço para as sugestões da turma, nunca desprezando o tempo para a discussão, explicitando e/ou construindo relações com a vida das crianças e sua comunidade. Essas são atitudes que se esperam de uma ação pedagógica arte educativa.

As alterações cognitivas que o vídeo proporciona estão geralmente relacionadas com a pessoa que o utiliza e não com a tecnologia em si. A sua introdução no processo de ensino/aprendizagem promove alterações não só no modo de pensar e de agir do professor, como também no modo

Revista Digital do LAV - Santa Maria - vol. 9, n. 1, p. 145 - 161. - jan./abr. 2016 ISSN 1983 - 7348 http://dx.doi.org/10.5902/1983734822001 
de aprender do aluno. Além de aprenderem conteúdos e desenvolverem competências, os alunos têm que conseguir pensar criticamente, desenvolver a capacidade para resolver problemas e trabalhar de forma autônoma ou colaborativa (SAMPAIO; COUTINHO, 2012, p. 28).

Consoante às proposições de Sampaio, voltemos o olhar a teoria de José Moran (1995, p. 29) a qual sugere que é comum o educador usar vídeos educativos, em sala, de maneira inadequada, sem provocar a reflexão do aluno apenas para atender às seguintes situações:

a) Vídeo tapa-buraco: colocar vídeo quando há um problema inesperado, como ausência do professor. Usar este expediente eventualmente pode ser útil, mas se for feito com frequência, desvaloriza o uso do vídeo e o associa, na cabeça do aluno, a não ter aula.

b) Vídeo enrolação: exibir um vídeo sem muita ligação com a matéria. $O$ aluno percebe que o vídeo é usado como forma de camuflar a aula. Pode concordar na hora, mas discorda do seu mau uso.

c) Vídeo deslumbramento: O professor que acaba de descobrir o uso do vídeo costuma se empolgar e passa vídeo em todas as aulas, esquecendo outras dinâmicas mais pertinentes.

d) Vídeo perfeição: Existem professores que questionam todos os vídeos possíveis porque possuem defeitos de informação ou estéticos. Os vídeos que apresentam conceitos problemáticos podem ser usados para descobri-los, junto com os alunos, e questioná-los.

e) Só vídeo: não é satisfatório didaticamente exibir o vídeo sem discutilo, sem integrá-lo com o assunto de aula, sem voltar e mostrar alguns momentos mais importantes.

Considerando tais inadequações na aplicação de vídeos educativos, propomos um roteiro simplificado e esquemático com algumas formas de trabalhar com vídeos diversos em sala de aula, todavia, o educador tem total liberdade para adaptar as propostas à realidade de seus alunos.

a) Vídeo como sensibilização: é um modelo interessantíssimo para introduzir um novo assunto porque desperta a curiosidade e motiva para dialogar sobre novos temas. Além disso, fomenta o desejo para a pesquisa e aprofundamento sobre o assunto do vídeo e/ou matéria.

b) Vídeo como ilustração: ajuda a mostrar o que se fala em aula, a compor cenários desconhecidos dos alunos. Por exemplo, um vídeo que exemplifica como era a arte em determinado período, mesmo que não seja 
totalmente fiel, ajuda a situar os alunos no tempo histórico. Ele pode trazer à sala de aula realidades distante dos alunos, por exemplo: a Amazônia ou a África. A vida se aproxima da escola através do vídeo.

c) Vídeo como simulação: É uma ilustração mais sofisticada. O vídeo pode simular experiências de química que seriam perigosas em laboratório ou que exigiriam muito tempo e recursos. Um vídeo pode mostrar o crescimento acelerado de uma planta, de uma árvore -da semente até a maturidade- em poucos segundos.

d) Vídeo como conteúdo de ensino: Vídeo que mostra determinado assunto, de forma direta ou indireta. De forma direta, quando informa sobre um tema específico orientando a sua interpretação. De forma indireta, quando mostra um tema, permitindo abordagens múltiplas, interdisciplinares.

Nesse sentido, "a tecnologia pode ser utilizada como eficiente instrumento (e veículo) [...] em toda a sociedade" (CUNHA, 2012, p. 20).

Neste contexto o sujeito pode aproveitar-se do You Tube para desenvolver a autonomia, fazer suas escolhas ressignificando valores, disseminando a utilização do vídeo na e-arte/educação em prol de manter a sociedade contemporânea e as mídias digitais interligadas, inseridas como meio de transmissão da cultura digital utilizando o vídeo.

\section{EXPLANANDO O VÍDEO: "PAI ME AJUDE, NASCI MENINA"}

O vídeo "Pai me ajude, nasci menina", caracteriza-se como um vídeo de sensibilização, um modelo interessante, normalmente usado quando o educador vai introduzir um novo assunto, tem como mérito principal despertar a curiosidade e motivar o diálogo sobre novos temas. Além disso, fomenta o desejo para a pesquisa e aprofundamento sobre o assunto do vídeo e/ou matéria trabalhada. 


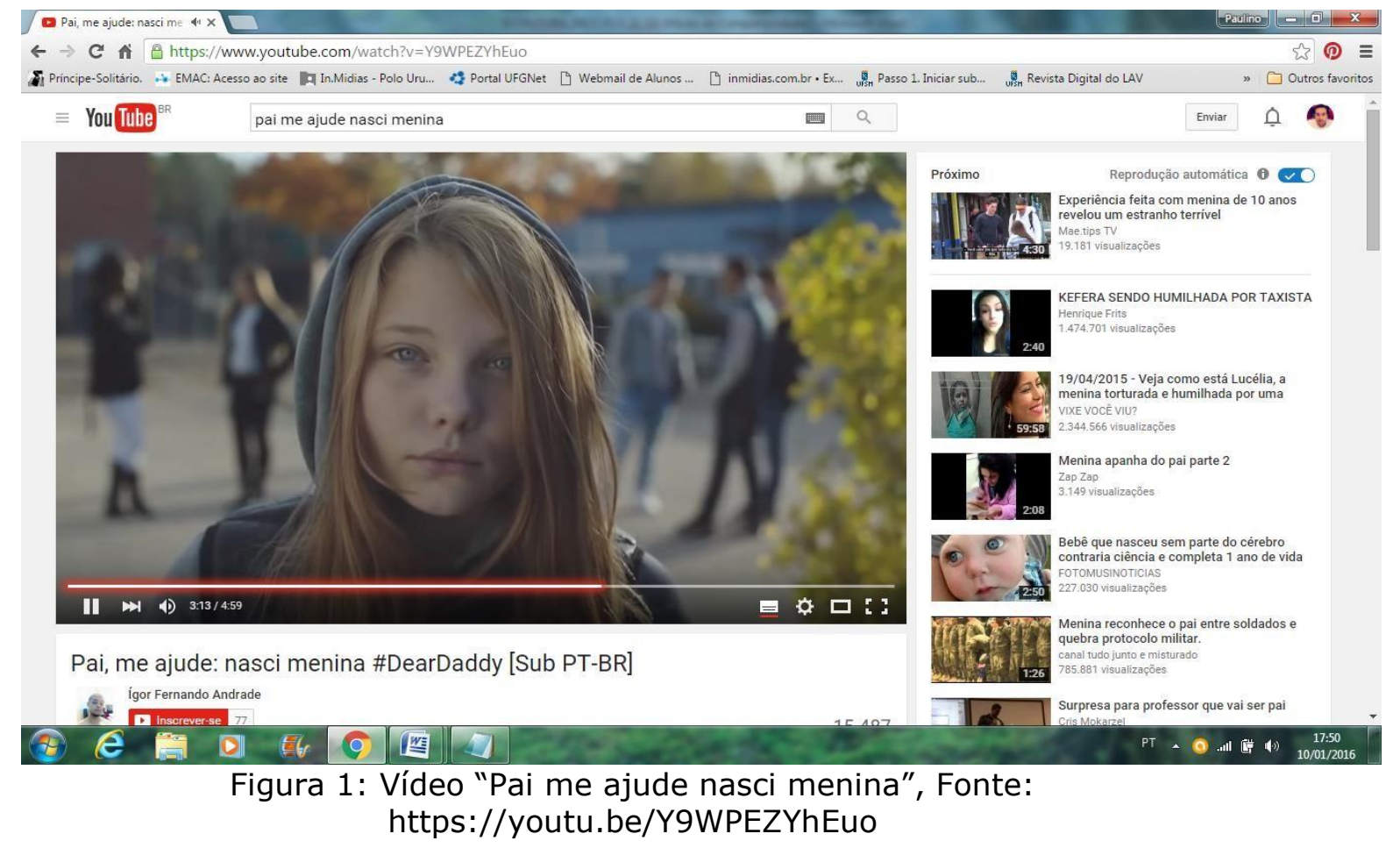

O vídeo começa com uma menina agradecendo ao pai por ter cuidado dela antes mesmo de ter nascido, logo no início ela avisa ao pai que precisa pedir um favor, um alerta: sobre garotos, depois disso ela começa a descrever situações de abuso sexual e psicológico como se fossem comuns para as mulheres e apenas uma brincadeira para os homens, na fase adulta ela começa a duvidar da sua própria sobriedade por conta das violências machistas sofridas na infância, em determinado momento do vídeo ela é agredida pelo companheiro, o vídeo se encaminha para o fim não pude deixar de trazer uma fala "então, querido pai, este é o favor que quero Ihe pedir. Uma coisa leva a outra. Então, por favor, não deixe que tudo isso comece. Não deixe meus irmãos chamares garotas de putas. Que um dia algum garotinho pode começar a acreditar nisso."

Os relatos de abuso que acontecem no vídeo se tornaram comuns porque ocorre muito cotidianamente na vida de adolescentes e devido a essa ocorrência se tornaram banais.

O papel da e-arte/educação neste contexto é este: pegar um ato do diaa-dia, ainda não pensado, trazendo uma reflexão para aquela ação, levar os alunos a desenvolver sua autonomia mudarem posturas, comportamentos dentro e fora da sala de aula.

Nessa relacionalidade complexa, podemos compreender os valores não lineares como ações contextualizadas. Assim a

Revista Digital do LAV - Santa Maria - vol. 9, n. 1, p. 145 - 161. - jan./abr. 2016 ISSN 1983 - 7348 http://dx.doi.org/10.5902/1983734822001 
definição de certo e errado passa pela questão da ambiência em um sentido contextual, urge a necessidade do exercício constante da capacidade crítica, para que ser estabeleçam valores, critérios e escolhas, e todos possam gerir com autonomia suas vidas, neste ambiente sistêmico de probabilidades improváveis. (CUNHA, 2012, p. 24).

Levando em consideração as reflexões de Cunha, é suscetível enfatizar a teoria de Dawsey (2005 apud TURNER 2013), que fala sobre a instalação da crise. O autor enfatiza que no drama social, a gente coloca um espelho para a pessoa se ver. E é essa ideia de crise que ao utilizar o vídeo como intento pedagógico, colocando os alunos para assistirem ao vídeo vai levá-los a desenvolver sua consciência crítica sobre a violência, sendo ela sexual ou não sexual. É comum eles estarem tão acostumados com a falta de respeito ao próximo que quando olharem o vídeo é possível que percebam essa falta de respeito, colocando frente ao problema.

Dawsey (2005) ressalta que no drama social, as sociedades percebem como elas sacaneiam a si mesmas, porque é naquele momento que a pessoa "cai em si" e percebe o que realmente está acontecendo. É a partir desse momento que ela pode mudar.

Utilizar o vídeo para alertar sobre o drama da violência sexual, o fato do vídeo não possuir um tema definido, faz com que as crianças exercitem o pensamento crítico.

"É neste eixo, portanto, que está engajada a educação intermidiática crítica por meio da e-arte/educação, da educação libertária promovendo a leitura crítica de um mundo descortinado, o desenvolvimento da consciência plena e crítica do mundo." (CUNHA, 2012, p. 27).

Considerando a reflexão da citação, pode-se dizer que, a princípio, assistindo ao vídeo, é possível que a pessoa pense que se trata da temática feminismo/machismo, mas quando a temática é aprofundada e assistindo com atenção, percebe que trata-se de acontecimentos do dia a dia e que de tanto acontecerem, tornaram-se comuns.

A escolha desse vídeo no You Tube para exposição neste estudo tem a função de tema a ser discutido com as crianças e sua aplicação na escola, além de possibilitar a visualização, é um tema instigante porque leva o aluno a pensar sobre seu cotidiano, em situações que de tão corriqueiras, passam a ser vistas 
como comuns.

\section{A ação pedagógica em "pai me ajude, nasci menina"}

Quanto à ação pedagógica, o planejamento ajuda o professor a situar as atividades dentro de sua programação, de modo a atingir os objetivos educacionais desejados.

O pedagogo retoma, então a questão inicial, da leitura da palavra e da leitura do mundo, que a percebe e que continua naquela. Sua proposta pedagógica passa justamente, afirma, pelo mesmo movimento fluido do mundo e da leitura e "escrita" que se faz dele, ou seja, a ação prática e consciente, que ele considera central para [...] contextualização (CUNHA, 2012, p. 192).

Sob essa ótica, é possível analisar a leitura de mundo do agente envolvido no processo. A ação precisa nortear o resultado, ou seja, o leitor competente deverá compreender a proposta e, ainda, decifrar o que é sugerido, cada um em seu espaço, por meio da prática apresentada e contextualizar a atividade com ações corriqueiras, isso gerará o desencadeamento das ideias e, ainda, influenciará à utilização do vídeo como ferramenta pedagógica apropriada e eficiente no processo ensino e aprendizagem.

$\mathrm{Na}$ aplicação do vídeo "Pai me ajude, nasci menina", é importante que o educador observe o tempo de que vai dispor para trabalhar o vídeo, o ideal é uma aula de 45 minutos. A ação pedagógica pode ser realizada com turmas do $9^{\circ}$ ano porque nesse nível adolescentes, entre 13 e 14 anos, já têm mais maturidade para fazer uma leitura crítica do que veem. Além disso, é uma fase da vida em que situações similares às apresentadas no vídeo acontecem não apenas na escola, mas em casa e em outros ambientes frequentados por esse público. A discussão pode ser feita no segundo semestre do ano letivo, quando a turma já se conhece bem e não existem entraves para o diálogo.

Freire (2011) fala sobre a leitura crítica do mundo, práticas capazes de desenvolver o agir crítico, a discussão em torno do conteúdo a ser trabalhado não deve tolher/induzir a interpretações dos participantes, uma vez que o vídeo é uma produção intencional, com visões de mundo e interesses determinados por seus autores. Neste sentido, a compreensão do assunto se relaciona com o modo de sentir e perceber o mundo, o que permite a inserção e o agir crítico.

Revista Digital do LAV - Santa Maria - vol. 9, n. 1, p. 145 - 161. - jan./abr. $2016 \quad$ ISSN 1983 - 7348 http://dx.doi.org/10.5902/1983734822001 


\section{Considerações finais}

A pesquisa faz perceber que a e-arte/educação digital crítica tem como objetivo retirar o sujeito da passividade em que há necessidade de existir o envolvimento do professor para formar alunos autônomos, automotivados, responsáveis, e por sua vez confiantes, onde eles abordarão a ação pedagógica para estimular seu conhecimento pleno e crítico sobre o vídeo e o assunto que ele retrata, avaliando com profundidade os conceitos aprendidos com a earte/educação digital crítica.

Levando em consideração as teorias analisadas, percebe-se que a ação pedagógica deve trazer esclarecimento do objetivo no momento de selecionar o vídeo e informar às crianças o que se espera ao final da discussão, deixando espaço para as sugestões da turma, nunca desprezando o tempo para a discussão, construindo relações com a vida das crianças. Essas são atitudes que se espera de uma ação pedagógica e-arte educativa, na qual o professor tem papel orientador e acompanha toda a ação para alcançar a participação dos alunos, levados ao problema, por meio da utilização do vídeo, possibilitando, assim a autonomia descrita por Cunha (2004), a qual sugere permitir a construção da consciência crítica.

Sobre a possibilidade de assistir o vídeo no celular, pode-se dizer que facilita a execução do processo, pelo fato de que se pode usar os aparelhos dos alunos e do professor, promovendo a curiosidade dos alunos, uma vez que aparelhos eletrônicos dão o privilégio de se trabalhar curiosidade e interatividade, simultaneamente, por meio de uma ação enriquecedora e que pode ser explorada em outras propostas e-arte/educativas para desenvolver a autonomia, com a oportunidade de envolver outros temas como: gamificação as redes sociais, a riqueza de funcionalidades do celular, temas que devem ser explorados pelo aluno, desde que isso o leve a desenvolver sua consciência crítica.

O estudo foi enriquecedor para orientar os alunos durante a ação pedagógica, percebeu-se, por meio da e-arte/educação o desenvolvimento da consciência crítica no processo de ensino/aprendizado com o uso do vídeo, potencializando o conhecimento com uma formação perceptiva, privilegiando o desenvolvimento da mente crítica por meio da imagem, som e debate.

O fato de assistir o vídeo proporciona o sentimento de modificação, o

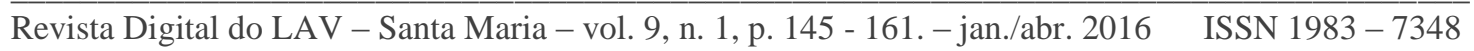
http://dx.doi.org/10.5902/1983734822001 
desejo de mudança, pegar um ato do dia-a-dia não pensado e modificá-lo, fazerse pensar, retirando assim o sujeito da passividade demonstra a efetivação de uma ação e-arte/educação crítica. O vídeo "Pai me ajude, nasci menina" relata a violência sofrida por uma garota, utiliza um ato corriqueiro como problemática e trabalha a ação pedagógica no desenvolvimento da autonomia. Conclui-se que o objeto de estudo, supracitado, enfatizou a existência de relevância a ser percorrida por um caminho possível de se trilhar com a utilização do vídeo no processo de ensino.

\section{Referências}

ADAMS, A., ROGERS, Y., COUGHLAN, T., VAN-DER-LINDEN, J., CLOUGH, G., MARTIN, E., \& COLLINS, T. Teenager needs in technology enhanced learning. Workshop on Methods of Working with Teenagers in Interaction Design, Paris, France: ACM Press, 2013.

BARBOSA, Ana M. T. Bastos. A imagem e o ensino da arte. São Paulo, Porto Alegre: Perspectiva, fundação Iochpe, 1991.

São Paulo: Cortez, 2008.

Arte/educação contemporânea. Consonâncias internacionais. 2. Ed.

BELL, R., 2013, Video reflection in teacher professional development. Consultado em 10/01/2016. Disponível em: <http://repositories.lib.utexas.edu/handle/2152/22433> Acesso em: 10 de jan. 2016.

BeTtentUIT, J. B., LISBÔA, E. S. \& COUTINHO, C. P. Percepção dos alunos sobre as potencialidades dos filmes e vídeos digitais na educação: uma experiência em dois cursos de licenciatura. Actas da VII Conferencia Internacional de TIC na Educação, Challenges, pp.873-885, Centro de Competência TIC do IE-UM, Braga, Universidade do Minho, 2013.

CASTELLS, M. A. sociedade em rede. São Paulo: Paz e Terra, 1999.

CUNHA, F. P. Técnica e tecnologia: a industria ideológica de massa. São Paulo: Annablume; Brasília: Capes, 2012.

CUNHA, F. P. Educação pelo olhar: aspectos das tecnologias do ensino intuitivo e da informática na arte/educação. 2004. Dissertação de Mestrado. Escola de Comunicações e Artes, Universidade de São Paulo, São Paulo, 2004.

- Cultura digital na e-arte/educação: educação digital crítica. 2008. Tese de Doutorado. Escola de Comunicações e Artes, Universidade de São Paulo, 2008.

Brasília: Capes, 2012b.

E-arte/educação: educação digital crítica. São Paulo: Annablume;

DAWSEY, J. C. Vitor Turner e antropologia da experiência. Cadernos de Campo: Revista dos Alunos de Pós-Graduação em Antropologia Social da USP, São Paulo,

Revista Digital do LAV - Santa Maria - vol. 9, n. 1, p. 145 - 161. - jan./abr. $2016 \quad$ ISSN $1983-7348$ http://dx.doi.org/10.5902/1983734822001 
n. 13, 2005.

FREIRE, P. Pedagogia do oprimido. Rio de Janeiro: Paz e Terra, 2011. . Pedagogia da autonomia: saberes necessários à prática educativa. Rio de Janeiro: Paz e Terra, 1999.

FERREIRA, M., OLIVEIRA, L., 2011. Autobiografia em vídeo: um estudo de caso com alunos do $6 . .^{\circ}$ ano de escolaridade. Livro de Atas da Conferência Internacional de TIC na Educação, Braga, 2011, pp. 859-870.

HEITINK, M., FISSER, P., MCKENNEY, S. Learning Literacy and Content Through Video Activities in Primary Education, in: P. Resta Ed. Proceedings of Society for Information Technology \& Teacher Education International Conference 2012, pp. 1363-1369. Chesapeake, ACE, 2012.

JORDAN, L., 2012, Video for peer feedback and reflection: embedding mainstream engagementinto learning and teaching practice. Research in Learning Technology, vol. 20, pp. 16-25.

KHALID, AZ, e MUHAMMAD, K, O Uso do YouTube em Ensino de Inglês Literatura O caso de Al-Majma'ah Community College, Al-Majma'ah University (Estudo de Caso), International Journal of Linguistics, vol. 4, no 4, pp.525, 2012.

REVISTA COMUNICAÇÃO \& EDUCAÇÃO. São Paulo: ECA-Ed. Moderna, [2]: 27 a 35, jan./abr. de 1995.

SAMPAIO, P., COUTINHO, C., , Avaliação do TPACK nas atividades de ensino e aprendizagem: um contributo para o estado da arte. Revista EducaOnline, Rio de Janeiro, v.6, no 3, p. 39-55, 2012.

TURNER, V. The forest of symbols. London: Cornell Press, 1967. The ritual process. London: Cornell Press, 1969.

.The Antropology of Performance.1987. Disponível

em:

<http://erikapaterson08.pbworks.com/f/Antrophology+of+performance $\% 282 \% 2$ 9.pdf>. Acesso em: 10 de jan. 2016.

YOUTUBE. Pai, me ajude: nasci menina \#DearDaddy. Disponível em: <https://youtu.be/Y9WPEZYhEuo>. Acesso em: 8 de jan. 2016. 